\title{
Long-term outcome of rotational atherectomy according to burr-to-artery ratio and changes in coronary artery blood flow: Observational analysis
}

\author{
Aleksander Nowak ${ }^{1}$, Jakub Ratajczak ${ }^{1,2}$ (D, Michał Kasprzak ${ }^{1}$, Adam Sukiennik ${ }^{1}$, \\ Tomasz Fabiszak ${ }^{1}$, Wojciech Wojakowski ${ }^{3}$, Andrzej Ochała ${ }^{3}$, Wojciech Wańha ${ }^{3}$, \\ Wacław Kuczmik ${ }^{4}$, Eliano Pio Navarese ${ }^{1}$ (i) Jacek Kubica $^{1}$ (D) \\ ${ }^{1}$ Department of Cardiology and Internal Medicine, Collegium Medicum, \\ Nicolaus Copernicus University, Bydgoszcz, Poland \\ ${ }^{2}$ Department of Health Promotion, Collegium Medicum, \\ Nicolaus Copernicus University, Bydgoszcz, Poland \\ ${ }^{3}$ Department of Cardiology and Structural Heart Diseases, \\ Medical University of Silesia, Katowice, Poland \\ ${ }^{4}$ Department of General and Vascular Surgery, Angiology and Phlebology, \\ Faculty of Katowice, Medical University of Silesia, Katowice, Poland
}

\begin{abstract}
Background: Rotational atherectomy (RA) has been proven to be efficient for the treatment of calcified and diffuse coronary artery lesions. However, the optimal burr-to-artery ratio (BtAR) remains unidentified as well as an influence of change in blood flow on long-term outcome. Aim of our study was to examine the association between long-term outcome, and both BtAR and change in coronary flow during RA. Methods: We conducted a retrospective study including patients who underwent $R A$. Two independent observers calculated BtAR, pre- and postprocedural corrected Thrombolysis in Myocardial Infarction (TIMI) frame count (cTFC) for artery treated with $R A$. The long-term outcome was defined as all-cause mortality.

Results: Receiver operating characteristic curve analysis of BtAR determined threshold of 0.6106 for all-cause mortality detection with sensitivity $50.0 \%$, specificity $90.8 \%$, and area under the curve 0.730 $(p<0.001)$. Kaplan-Meier survival analysis showed that the all-cause mortality rate in the group with the BtAR $>0.6106$ is significantly higher compared to the patients with lower BtAR (hazard ratio [HR] 3.76, 95\% confidence interval [CI] 1.51-9.32; $p<0.001)$. Kaplan-Meier survival analysis revealed that the all-cause mortality rate in the group with impairment in coronary flow was significantly higher compared to group with cTFC difference $\leq 0$ after RA (HR 3.28, 95\% CI 1.56-9.31; $p=0.02$ ).

Conclusions: Burr-to-artery ratio $>0.6106$ is associated with worse prognosis of patients treated with RA. Patients showing post-RA impairment in blood flow in the target artery have worse prognosis. (Cardiol J)
\end{abstract}

Key words: rotational atherectomy, burr-to-artery ratio, corrected Thrombolysis in Myocardial Infarction frame count, mortality

Address for correspondence: Jakub Ratajczak, MD, Department of Cardiology and Internal Medicine/Department of Health Promotion, Nicolaus Copernicus University, Collegium Medicum in Bydgoszcz, ul. Marii Skłodowskiej-Curie 9, 85-094 Bydgoszcz, Poland, tel.: +48 5258540 23; fax: +48 5258540 24, e-mail: ratajczak.j.m@gmail.com

Received: 4.02 .2021

Accepted: 4.07.2021

Early publication date: 2.08 .2021

This article is available in open access under Creative Common Attribution-Non-Commercial-No Derivatives 4.0 International (CC BY-NC-ND 4.0) license, allowing to download articles and share them with others as long as they credit the authors and the publisher, but without permission to change them in any way or use them commercially. 


\section{Introduction}

Over the past decades rotational atherectomy (RA) has been proven to be a safe and efficient method for treatment of calcified and diffuse coronary artery lesions [1-4]. Nevertheless, this strategy is still uncommonly used, with an application rate as low as $0.8-3.1 \%$ of total percutaneous coronary interventions (PCI) in Europe [1]. In the Polish PCI registry, this value was even lower and amounted only $0.44 \%$ of PCI procedures $[5,6]$. As demonstrated by previous studies, patients undergoing RA are significantly older than those treated with standard PCI [1]. Therefore, ageing of the population of cardiovascular patients should prompt resurgence of interest in RA that may even grow in the next years. Despite technological progress including the introduction of very high pressure and low-profile balloons, laser and orbital atherectomy, RA still occupies the first place among plaque modification techniques [4].

The technique of performing RA has evolved over the years. Although more aggressive debulking strategy with bigger burr sizes and burr-to-artery ratio $(\mathrm{BtAR})>0.7$ was preferred in the past, the current guidelines recommend an opposite approach called "plaque modification strategy" based on using smaller burrs, with BtAR 0.5-0.6 [1, 2]. Previous studies showed that smaller burr sizing (BtAR $<0.7)$, compared with a more aggressive strategy, was related with similar procedural and angiographic success rates, but was burdened with less angiographic complications and lower creatine kinase-myocardial band release during the procedure $[7,8]$. There are only scarce literature data comparing both strategies in terms of long-term outcomes.

The incidence of coronary artery flow impairment in patients treated with RA is higher than after standard PCI [9-11]. There are several underlying mechanisms of this phenomenon, such as microcirculatory vasospasm, enhanced platelet activation and aggregation, and microvascular embolization of atherosclerotic debris [9, 12]. The occurrence of slow-flow in coronary arteries is usually associated with poor technique and inadequate burr size [1]. Administration of intracoronary nitrates, verapamil, sodium nitroprusside, or adenosine can improve the blood flow during the procedure [9, 12-14]. Previous studies showed that the occurrence of slow-flow is correlated with worse long-term prognosis [15]. However, significant slow-flow, defined as postprocedural grade 0 or 1 according to Thrombolysis in Myocardial Infarction (TIMI) scale, is infrequent and occurs in $0.0-2.6 \%$ of cases [2]. The TIMI scale is an inaccurate and operator-dependent method, nevertheless, it is still commonly used for assessment of postprocedural coronary blood flow and even despite clear slowing of the blood flow is often judged as TIMI 3 [16]. In our study, we focused on BtAR as a key difference between debulking and plaque modification strategies and on difference in post-RA coronary flow in the target vessel. The aim of our study was to examine whether BtAR and coronary flow after the procedure are associated with long-term outcomes in patients undergoing RA.

\section{Methods}

\section{Study design and patients}

This is a retrospective, double-center study including patients who underwent RA at the Department of Cardiology and Internal Medicine of the University Hospital No. 1 in Bydgoszcz and at the Department of Cardiology and Structural Heart Diseases of the Medical University of Silesia in Katowice between January 2005 and February 2017. During that time period a total of 232 RA procedures were performed. Procedural success was defined as success in facilitating stent delivery with residual stenosis $<50 \%$ and without severe procedural complication (e.g., inability to insert guiding catheter/rotablator burr through the stenotic lesion or occurrence of severe dissection/perforation). The procedures assessed as unsuccessful were not included in the further analysis. 52 cases were excluded and 180 patients were eventually enrolled with stenosis treated with RA for the analysis. The exclusion criteria were more than one RA procedure in a single patient $(\mathrm{n}=6)$, unsuccessful passage of the burr through the stenotic lesion $(n=7)$ or inability to calculate BtAR due to technical issues $(n=39)$. The analysis of coronary blood flow changes was performed, with data limited to the center in Bydgoszcz. 21 patients were excluded, (12 patients) due to inability to calculate the corrected TIMI frame count (cTFC) before and after the procedure, or administration of glycoprotein IIb/IIIa inhibitors during RA (9 patients). The need for performing RA in each case was evaluated by the operator based on two main indications: presence of uncrossable lesions and inability to sufficiently dilate the lesion with a balloon. In cases when more than one burr size was used the largest size was included in the analysis. All study participants received pharmacotherapy according to the recommendations of the European Society of Cardiology valid at the time of the procedure. Clinical and procedural data were collected from patient medical records. Follow-up data 
Table 1. Baseline clinical characteristics of the study population including division according to burr-to-artery-ratio (BtAR) threshold.

\begin{tabular}{lcccc}
\hline & $\begin{array}{c}\text { All patients enrolled } \\
\text { in the study }(\mathbf{n}=\mathbf{1 8 0})\end{array}$ & $\begin{array}{c}\text { BtAR } \leq \mathbf{0 . 6 1 0 6} \\
(\mathbf{n}=152)\end{array}$ & $\begin{array}{c}\text { BtAR }>0.6106 \\
(\mathbf{n}=28)\end{array}$ & P \\
\hline Male sex & $117(65.0 \%)$ & $97(63.8 \%)$ & $20(71.4 \%)$ & 0.58 \\
Age & $71.8(9.0)$ & $72.0(9.0)$ & $70.6(9.1)$ & 0.45 \\
Hypertension & $136(75.6 \%)$ & $119(78.3 \%)$ & $17(60.7 \%)$ & 0.08 \\
Diabetes & $96(53.3 \%)$ & $85(55.9 \%)$ & $11(39.3 \%)$ & 0.16 \\
Prior Ml & $91(50.6 \%)$ & $78(51.3 \%)$ & $13(46.4 \%)$ & 0.79 \\
Body mass index & $28.2(4.6)$ & $28.3(4.4)$ & $27.8(4.1)$ & 0.62 \\
Ejection fraction & $50(39.75-55.0)$ & $50(39.5-55.0)$ & $43(39.0-51.0)$ & 0.37 \\
\hline
\end{tabular}

Mean values (standard deviation), median (interquartile range), or number (\%); MI — myocardial infarction

were collected from the Polish National Health Fund database. The study was conducted in accordance with the Declaration of Helsinki and Good Clinical Practice guidelines and was approved by the Ethics Committee of Nicolaus Copernicus University in Torun, Collegium Medicum in Bydgoszcz (approval number KB 56/2020). The primary clinical endpoint was defined as all-cause mortality.

\section{Angiograms}

Two independent observers in both centers trained in angiogram assessment and blinded to other clinical data, calculated BtAR. The definition and calculation method of BtAR was similar as reported in previous studies [17]. The measurements from both observers were then averaged to give the final result. The cTFC was defined as the number of frames required for contrast dye to reach the first standard distal coronary landmark and was evaluated using the technique described by Gibson et al. [16]. The difference between the postprocedural and preprocedural CTFC was evaluated to reflect the changes in coronary artery blood flow. Both preprocedural and postprocedural cTFC were examined directly before and after RA, respectively. All angiograms were registered at 12.5 frames/s. All disputable issues and disagreements were resolved by a third independent observer. The primary angiographic endpoint was defined as post-RA cTFC. The angiograms were analyzed using OsiriX Lite software (Pixmeo SARL) and CAAS QCA software (Pie Medical Imaging BV).

\section{Statistical analysis}

The statistical analysis was performed using the Statistica 13.0 package (StatSoft, Tulsa, USA) and MedCalc 15.8 (MedCalc Software, Ostend, Belgium). Continuous variables were presented as medians with interquartile ranges or means with standard deviation (SD). Categorical variables were expressed as the number of patients presenting the given feature and the percentage of patients in the analyzed group. The optimum cut-off points for the association between BtAR and all-cause mortality was determined using receiver operator characteristics curve analysis. The Shapiro-Wilk test demonstrated that the continuous variables investigated were not normally distributed. Therefore, comparisons of continuous variables between the two groups were analyzed with the Mann-Whitney unpaired rank sum test. Categorical variables were compared using the $\chi^{2}$ test and with the Yates' correction if required. The survival analyses were performed with the Kaplan-Meier method and the log-rank test. Aforementioned calculations were made for a 6 -year time period (from the procedure to patient's death) because after that time period the number of patients remaining in the analysis group was very limited and could potentially increase the risk of calculation bias. Differences were considered significant at $\mathrm{p}<0.05$.

\section{Results}

\section{Baseline characteristics}

The mean age (SD) in the study group was 71.8 (9.0) years with a prevalence of men $(65.0 \%)$. The mean BtAR (SD) was 0.4951 (0.1158). A total of $28(15.6 \%)$ patients died with a mean (SD) of 745.2 (848.1) days from the procedure to death. Detailed characteristics of the study population is presented in Table 1.

\section{Burr-to-artery ratio}

The optimal BtAR cut-off point for prediction of all-cause mortality was 0.6106 (sensitivity 
Table 2. Angiographic characteristics of the study population including division according to burr-to-artery-ratio (BtAR) threshold.

\begin{tabular}{|c|c|c|c|c|}
\hline & $\begin{array}{l}\text { All patients } \\
\text { enrolled in the } \\
\text { study }(n=180)\end{array}$ & $\begin{array}{c}\text { BtAR } \leq 0.6106 \\
(n=152)\end{array}$ & $\begin{aligned} \text { BtAR } & >0.6106 \\
(n=28) & =28\end{aligned}$ & $\mathbf{P}$ \\
\hline Duration of the procedure [min] & $80.0(60.0-110.0)$ & $80.0(60.0-110.0)$ & $66.0(58.5-98.5)$ & 0.31 \\
\hline Contrast volume [mL] & $200.0(150.0-250.0)$ & $200.0(150.0-250.0)$ & $210.0(155.0-260.0)$ & 0.32 \\
\hline $\begin{array}{l}\text { Location of treated stenosis: } \\
\text { LAD }\end{array}$ & $70(38.9 \%)$ & $62(40.8 \%)$ & $8(28.6 \%)$ & 0.86 \\
\hline $\mathrm{RCA}$ & $57(31.7 \%)$ & $50(32.9 \%)$ & $7(25.0 \%)$ & 0.54 \\
\hline $\mathrm{Cx}$ & $39(21.6 \%)$ & $29(19.1 \%)$ & $10(35.7 \%)$ & 0.09 \\
\hline OM & $14(7.8 \%)$ & $11(7.2 \%)$ & $3(10.7 \%)$ & 0.80 \\
\hline Burr size $[\mathrm{mm}]$ & $1.5(1.25-1.5)$ & $1.5(1.25-1.5)$ & $1.5(1.25-1.75)$ & 0.006 \\
\hline Minimum stent diameter [mm] & $2.75(2.5-3.0)$ & $2.75(2.5-3.0)$ & $2.5(2.25-3.0)$ & 0.03 \\
\hline Maximum stent diameter [mm] & $3.0(2.5-3.5)$ & $3.0(2.75-3.5)$ & $2.5(2.5-3.5)$ & 0.02 \\
\hline Average stent diameter $[\mathrm{mm}]^{*}$ & $3.0(2.5-3.25)$ & $3.0(2.67-3.25)$ & $2.5(2.5-3.0)$ & 0.01 \\
\hline Usage of glycoprotein Ilb/IIla inhibitors & $16(8.9 \%)$ & $12(7.9 \%)$ & $4(14.3 \%)$ & 0.47 \\
\hline Total stent length [mm] & $38.0(22.0-52.0)$ & $38.0(23.0-52.0)$ & $42.0(18.0-59.0)$ & 0.74 \\
\hline Catheter size [Fr]: & & & & 0.009 \\
\hline 6 & $66.7 \%$ & $66.5 \%$ & $67.8 \%$ & \\
\hline 7 & $27.2 \%$ & $29.6 \%$ & $14.3 \%$ & \\
\hline 8 & $6.1 \%$ & $3.9 \%$ & $17.9 \%$ & \\
\hline
\end{tabular}

Values are median (interquartile range) or number $(\%) ;{ }^{*}$ In case of implantation more than one stent in target vessel an average diameter for all implanted stents was calculated; LAD — left anterior descending artery; RCA — right coronary artery; Cx - circumflex coronary artery; $\mathrm{OM}$ - obtuse marginal artery

$50.0 \%$, specificity $90.8 \%$, area under curve 0.730 ; $\mathrm{p}<0.001)$. Based on this BtAR threshold, the patients were divided into two groups, with the majority of them (84.4\%) falling into the BtAR $\leq 0.6106$ group. Both groups did not differ in terms of baseline clinical characteristics (Table 1). Duration of the procedure and location of stenosis were similar in both groups (Table 2). For patients with BtAR $\leq 0.6106$ smaller burrs (median burr size 1.5 [1.25-1.5 ] vs. 1.5 [1.25-1.75], $\mathrm{p}=0.006$ ), larger stents (minimum stent diameter [mm]: 2.75 [2.5-3.0] vs. 2.5 [2.25-3.0], $\mathrm{p}=0.03$; maximum stent diameter [mm]: 3.0 [2.75-3.5] vs. 2.5 [2.5-3.5], $\mathrm{p}=0.02$; median stent diameter $[\mathrm{mm}]: 3.0[2.67$ -3.25 ] vs. 2.5 [2.5-3.0], $\mathrm{p}=0.01)$ and smaller catheters were used (catheter size [Fr]: 6 [66.5\%], 7 [29.6\%], 8 [3.9\%] vs. 6 [67.8\%], 7 [14.3\%], 8 [17.9\%], $\mathrm{p}=0.009$ ).

The Kaplan-Meier survival analysis (Fig. 1) showed a significantly higher all-cause mortality rate in the group with BtAR $>0.6106$ compared with the patients with a lower BtAR (hazard ratio [HR] 3.76, 95\% confidence interval [CI] 1.51-9.32; $\mathrm{p}<0.001)$.

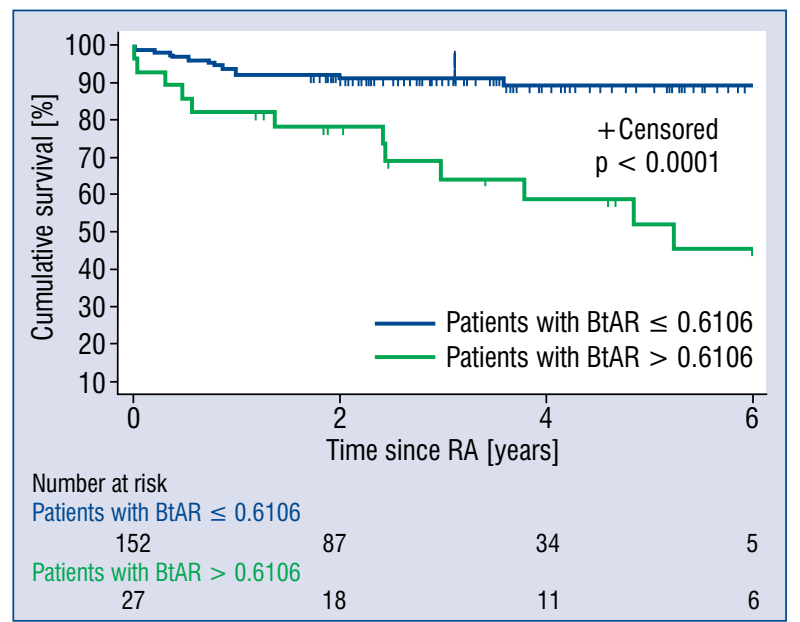

Figure 1. Survival after rotational atherectomy (RA) by burr-to-artery ratio (BtAR) after division into two groups.

\section{Changes in coronary artery blood flow}

A total of 62 patients for whom the cTFC was evaluated were divided into two groups based on the difference between the postprocedural and preprocedural values of cTFC. Patients showing impairment 
Table 3. Baseline clinical and angiographic characteristics of the study population regarding corrected Thrombolysis in Myocardial Infarction frame count (cTFC) difference.

\begin{tabular}{|c|c|c|c|c|}
\hline & $\begin{array}{l}\text { All patients enrolled } \\
\text { in the study }(n=62)\end{array}$ & $\begin{array}{c}\text { cTFC difference } \leq 0 \\
(n=38)\end{array}$ & $\begin{array}{c}\text { cTFC difference }>0 \\
(n=24)\end{array}$ & $\mathbf{P}$ \\
\hline Male sex & $38(61.3 \%)$ & $21(55.3 \%)$ & $17(70.8 \%)$ & 0.22 \\
\hline Age & $71.1(9.0)$ & $72.7(8.9)$ & $68.5(8.8)$ & 0.07 \\
\hline Arterial hypertension & $42(67.7 \%)$ & $25(65.8 \%)$ & $17(70.8 \%)$ & 0.84 \\
\hline Diabetes type 2 & $33(53.2 \%)$ & $17(44.7 \%)$ & $16(66.7 \%)$ & 0.12 \\
\hline Prior MI & $30(48.4 \%)$ & $16(42.1 \%)$ & $14(58.3 \%)$ & 0.26 \\
\hline Body mass index & $28.3(4.5)$ & $29.3(4.7)$ & $26.7(3.9)$ & 0.04 \\
\hline Ejection fraction & 42.5 (38.0-49.) & $40(35.5-49.25)$ & $47(41.25-49.0)$ & 0.17 \\
\hline Duration of the procedure [min] & $65.0(50.0-90.0)$ & $65.0(55.0-90.0)$ & $60.0(50.0-90.5)$ & 0.56 \\
\hline Contrast volume $[\mathrm{mL}]$ & $182.0(140.0-270.0)$ & $182.0(145.0-261.0)$ & $180.0(137.5-278.0)$ & 0.79 \\
\hline \multicolumn{5}{|l|}{ Location of treated stenosis: } \\
\hline LAD & $9(14.5 \%)$ & $7(18.4 \%)$ & $2(8.3 \%)$ & 0.47 \\
\hline RCA & $23(37.1 \%)$ & $14(36.8 \%)$ & $9(37.5 \%)$ & 0.96 \\
\hline Cx & $20(32.6 \%)$ & $13(34.2 \%)$ & $7(29.2 \%)$ & 0.68 \\
\hline OM1 & $7(11.3 \%)$ & $4(10.5 \%)$ & $3(12.5 \%)$ & 0.86 \\
\hline OM2 & $3(4.8 \%)$ & $0(0 \%)$ & $3(12.5 \%)$ & 0.28 \\
\hline Burr size [mm] & $1.25(1.25-1.5)$ & $1.25(1.25-1.5)$ & $1.5(1.25-1.5)$ & 0.12 \\
\hline Minimum stent diameter [mm] & $2.5(2.5-3.0)$ & $2.5(2.375-3.0)$ & $2.625(2.5-3.0)$ & 0.57 \\
\hline Maximum stent diameter [mm] & $3.0(2.5-3.5)$ & $3.0(2.5-3.5)$ & $3.0(2.5-3.5)$ & 0.21 \\
\hline Average stent diameter $[\mathrm{mm}]^{*}$ & $2.8(2.5-3.0)$ & $2.775(2.5-3.0)$ & $3.0(2.5-3.25)$ & 0.27 \\
\hline Total stent length $[\mathrm{mm}]$ & $38.5(20.0-51.5)$ & $40.5(23.0-53.0)$ & $38.0(19.5-50.0)$ & 0.79 \\
\hline \multicolumn{5}{|l|}{ Catheter size [Fr]: } \\
\hline 6 & $71.0 \%$ & $71.0 \%$ & $70.8 \%$ & 0.42 \\
\hline 7 & $22.6 \%$ & $23.7 \%$ & $20.8 \%$ & \\
\hline 8 & $6.4 \%$ & $5.3 \%$ & $8.3 \%$ & \\
\hline Burr-to-artery ratio & $\begin{array}{c}0.5364 \\
(0.4668-0.6476)\end{array}$ & $\begin{array}{c}0,5177 \\
(0.4561-0.6476)\end{array}$ & $\begin{array}{c}0,5637 \\
(0.4940-0.6449)\end{array}$ & 0.24 \\
\hline
\end{tabular}

Mean values (standard deviation), median (interquartile range) or number (\%); ${ }^{*}$ In case of implantation more than one stent in target vessel an average diameter for all implanted stents was calculated; $\mathrm{MI}$ - myocardial infarction; LAD — left anterior descending artery; RCA — right coronary artery; Cx - circumflex coronary artery; OM1 — first obtuse marginal artery; OM2 - second obtuse marginal artery

in blood flow in the target artery (cTFC difference $>0$ ) had a lower body mass index (mean [SD], 26.7 [3.9] vs. 29.8 [4.7], $p=0.04$ ) with no other baseline or procedural differences in comparison to patients presenting cTFC difference $\leq 0$ (Table 3 ).

The Kaplan-Meier survival analysis (Fig. 2) revealed a significantly higher all-cause mortality rate in the group with impaired post-RA coronary artery blood flow (cTFC difference $>0$ ) compared with patients with preserved coronary flow with cTFC difference $\leq 0$ (HR 3.28, 95\% CI 1.56-9.31; $\mathrm{p}=0.02$ ).

\section{Discussion}

The main finding of this study is that BtAR higher than 0.6106 and impaired postprocedural coronary flow (cTFC difference $>0$ ) are associated with almost 4-times and over 3-times higher risk of mortality in those groups, respectively.

The increase in mortality found in cases with higher BtAR can be explained by a higher complication rate associated with a more aggressive debulking strategy [7]. Other potential causes of this phenomenon include higher debris production, increased platelet activation and aggregation, microvascular embolization resulting in heart systolic dysfunction [18]. The optimal BtAR remains unidentified, however the current guidelines recommend the burr size of $<0.7$ [1] or $<0.6$ [2] of the vessel diameter. Recently published studies reflecting implementation of recommendations into clinical practice reported the BtAR $<0.6$ 


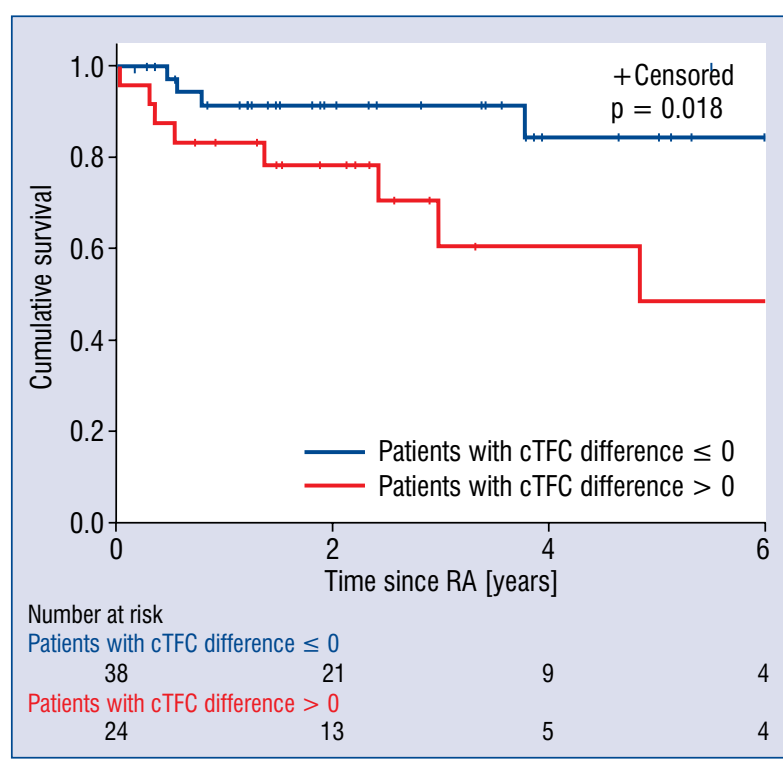

Figure 2. Survival after rotational atherectomy (RA) by changes in coronary blood flow; cTFC - corrected Thrombolysis in Myocardial Infarction frame count.

$[3,19,20]$ or even $<0.5[21,22]$ for the overall study population. The mean BtAR (SD) calculated for all patients in the present study was 0.50 (0.12). The beneficial effect of RA performed with lower BtAR has been demonstrated in previously published studies [7, 17, 20]. One of the earliest studies regarding RA, by Kaplan et al. [17], revealed that the need for vessel revascularization is decreased in patients with BtAR 0.6-0.85. Randomized CARAT trial [7] revealed that RA performed with smaller burrs $(\mathrm{BtAR} \leq 0.7)$ provided similar procedural success, but with a lower angiographic complication rate, in comparison to a more aggressive strategy. Cuenza et al. [20] reported significantly higher BtAR in patients who developed major adverse events. In the current study, patients with higher BtAR had worse long-term prognosis, thus supporting the need for less aggressive treatment. Despite benefits of a smaller burr sizing, evidence regarding the lower limit of optimal BtAR range is very scarce. Brown et al. [23] demonstrated that RA performed even with $\mathrm{BtAR}<0.5$ can provide low complication and high success rates. Therefore, in order to find the optimal burr size, it is recommended to start RA with the smallest possible burr size and increase it until a favorable result is achieved [1,2].

In order to overcome the subjectivity and imprecision of the TIMI scale, the cTFC difference was used as a more precise and objective tool for assessment of coronary blood flow [16]. It was found that impairment of coronary blood flow was correlated with higher mortality.

Several studies [24-30] investigated the influence of preprocedural or postprocedural blood flow in the target artery on short and long-term outcome, but the majority focused on patients with myocardial infarction for whom RA is rather the last interventional option [19]. According to available research, this is the first study to evaluate the association between a change in coronary blood flow during RA and long-term outcomes.

The results of the GUSTO IIb [31] and RAPPORT [32] trials showed that patients with suboptimal coronary blood flow (TIMI $\leq 2$ ) after primary PCI had worse prognosis (with mortality rates of TIMI 3 vs. TIMI $\leq 2$ of $1.5 \%$ and $10.2 \%$, respectively, $\mathrm{p}<0.001$ ) during 30 days of observation. De Luca et al. [25] noted that in high-risk patients treated with primary PCI due to acute myocardial infarction the preprocedural TIMI flow grade 3 was an independent predictor of 1 -year survival. Mehta et al. [26] reported a strong association between final TIMI grade $\leq 2$ and both in-hospital and 1-year adverse events, although they noticed that TIMI $\leq 2$ which occurred less commonly after primary PCI. A study by Ndrepepa et al. [27] revealed an association between postprocedural TIMI flow grade and 1-year mortality in patients with acute coronary syndrome treated with PCI, however no correlation was found between preprocedural TIMI score and mortality.

Gibson et al. [28] demonstrated lower 90-minute cTFC after thrombolysis administration to be a predictor of improved in-hospital and 1-month clinical outcomes [28] and 2-year survival [29]. Importantly, the authors noticed that among patients with normal coronary blood flow (TIMI grade 3 , cTFC $\leq 40$ ), there may be lower- and higher-risk subgroups [28]. Although thrombolytic therapy is currently not recommended for patients with myocardial infarction as a primary strategy, this finding should be taken into consideration regarding the results of the present study, since normal flow after RA was observed in the vast majority of patients (98.4\% and $93.5 \%$ according to the TIMI scale or cTFC, respectively). French et al. [30] showed that the cTFC (3 weeks after myocardial infarction) is an independent predictor of 5-year survival, however no relationship was found regarding 10 -year survival. The authors reported also that the cTFC method, although yielding additional prognostic information, was not superior to TIMI flow grade. 


\section{Limitations of the study}

Several limitations of the present study should be noted. The main limitation of the present study is its retrospective design. On the other hand, the use of objective quantitative data as the BtAR and the mortality hard endpoint can mitigate potential confounding arising from a retrospective design. The next limitation is a relatively low number of patients included in the final analysis. Nevertheless, it should be underlined that RA is remains a rarely performed procedure, especially in Poland. Therefore this study showed results of one of the largest Polish cohorts of patients who underwent this procedure. Another limitation, potentially influencing the results, is the extended duration of study period, possibly resulting in heterogeneity of the study population with regard to the evolution of available procedural techniques and pharmacotherapy over the last decade. Furthermore, only all-cause mortality data were able to be retrieved, which rendered a complementary analysis of cardiovascular deaths impossible. Finally, the cTFC parameter difference introduced in the current study, although prognostically useful, is timeconsuming to calculate and therefore its use in everyday practice may be limited.

\section{Conclusions}

This is the first study to evaluate the association between long-term outcome of patients treated with RA and BtAR as well as changes in coronary blood flow. The BtAR higher than 0.6106 and impairment of blood flow assessed with the cTFC difference were associated with worse survival.

\section{Conflict of interest: None declared}

\section{References}

1. Barbato E, Carrié D, Dardas P, et al. European expert consensus on rotational atherectomy. EuroIntervention. 2015; 11(1): 30-36, doi: 10.4244/EIJV11I1A6, indexed in Pubmed: 25982648.

2. Tomey MI, Kini AS, Sharma SK. Current status of rotational atherectomy. JACC Cardiovasc Interv. 2014; 7(4): 345-353, doi: 10.1016/j.jcin.2013.12.196, indexed in Pubmed: 24630879.

3. Abdel-Wahab M, Baev R, Dieker P, et al. Long-term clinical outcome of rotational atherectomy followed by drug-eluting stent implantation in complex calcified coronary lesions. Catheter Cardiovasc Interv. 2013; 81(2): 285-291, doi: 10.1002/ccd.24367, indexed in Pubmed: 22431433.

4. Kübler P, Reczuch K. Calcified lesions treated with rotational atherectomy-much more advantages than real hazards. J Thorac Dis. 2018; 10(Suppl 26): S3215-S3217, doi: 10.21037/ jtd.2018.08.62, indexed in Pubmed: 30370116.
5. Januszek RA, Dziewierz A, Siudak Z, et al. Diabetes and periprocedural outcomes in patients treated with rotablation during percutaneous coronary interventions. Cardiol J. 2020; 27(2): 152-161, doi: 10.5603/CJ.a2018.0102, indexed in Pubmed: 30234901.

6. Januszek RA, Dziewierz A, Siudak Z, et al. Predictors of periprocedural complications in patients undergoing percutaneous coronary interventions within coronary artery bypass grafts. Cardiol J. 2019; 26(6): 633-644, doi: 10.5603/CJ.a2018.0044, indexed in Pubmed: 29671862.

7. Safian RD, Feldman T, Muller DW, et al. Coronary angioplasty and Rotablator atherectomy trial (CARAT): immediate and late results of a prospective multicenter randomized trial. Catheter Cardiovasc Interv. 2001; 53(2): 213-220, doi: 10.1002/ccd.1151, indexed in Pubmed: 11387607.

8. Whitlow P, Bass T, Kipperman R, et al. Results of the study to determine rotablator and transluminal angioplasty strategy (STRATAS). Am J Cardiol. 2001; 87(6): 699-705, doi: 10.1016/ s0002-9149(00)01486-7.

9. Eeckhout E, Kern MJ. The coronary no-reflow phenomenon: a review of mechanisms and therapies. Eur Heart J. 2001; 22(9): 729-739, doi: 10.1053/euhj.2000.2172, indexed in Pubmed: 11350105.

10. Piana RN, Paik GY, Moscucci M, et al. Incidence and treatment of ,no-reflow' after percutaneous coronary intervention. Circulation. 1994; 89(6): 2514-2518, doi: 10.1161/01.cir.89.6.2514, indexed in Pubmed: 8205658.

11. Abbo KM, Dooris M, Glazier S, et al. Features and outcome of noreflow after percutaneous coronary intervention. Am J Cardiol. 1995; 75(12): 778-782, doi: 10.1016/s0002-9149(99)80410-x, indexed in Pubmed: 7717278.

12. Rezkalla SH, Kloner RA. No-reflow phenomenon. Circulation. 2002; 105(5): 656-662, doi: 10.1161/hc0502.102867, indexed in Pubmed: 11827935.

13. Cohen BM, Weber VJ, Blum RR, et al. Cocktail attenuation of rotational ablation flow effects (CARAFE) study: pilot. Cathet Cardiovasc Diagn. 1996; Suppl 3: 69-72, indexed in Pubmed: 8874932.

14. Matsuo H, Watanabe S, Watanabe T, et al. Prevention of noreflow/slow-flow phenomenon during rotational atherectomy: a prospective randomized study comparing intracoronary continuous infusion of verapamil and nicorandil. Am Heart J. 2007; 154(5): 994.e1-994.e6, doi: 10.1016/j.ahj.2007.07.036, indexed in Pubmed: 17967610.

15. Resnic FS, Wainstein M, Lee MKY, et al. No-reflow is an independent predictor of death and myocardial infarction after percutaneous coronary intervention. Am Heart J. 2003; 145(1): 42-46, doi: 10.1067/mhj.2003.36, indexed in Pubmed: 12514653.

16. Gibson CM, Cannon CP, Daley WL, et al. TIMI frame count: a quantitative method of assessing coronary artery flow. Circulation. 1996; 93(5): 879-888, doi: 10.1161/01.cir.93.5.879, indexed in Pubmed: 8598078.

17. Kaplan BM, Safian RD, Mojares JJ, et al. Optimal burr and adjunctive balloon sizing reduces the need for target artery revascularization after coronary mechanical rotational atherectomy. Am J Cardiol. 1996; 78(11): 1224-1229, doi: 10.1016/s00029149(96)00600-5, indexed in Pubmed: 8960579.

18. Reffelmann T, Kloner RA. The "no-reflow" phenomenon: basic science and clinical correlates. Heart. 2002; 87(2): 162-168, doi: 10.1136/heart.87.2.162, indexed in Pubmed: 11796561. 


\section{Cardiology Journal}

19. Allali A, Abdelghani M, Mankerious N, et al. Feasibility and clinical outcome of rotational atherectomy in patients presenting with an acute coronary syndrome. Catheter Cardiovasc Interv. 2019; 93(3): 382-389, doi: 10.1002/ccd.27842, indexed in Pubmed: 30196568 .

20. Cuenza LR, Jayme AC, Khe Sui JHo. Clinical Outcomes of Patients Undergoing Rotational Atherectomy Followed by Drugeluting Stent Implantation: A Single-center Real-world Experience. Heart Views. 2017; 18(4): 115-120, doi: 10.4103/1995705X.221231, indexed in Pubmed: 29326773.

21. Schwartz BG, Mayeda GS, Economides C, et al. Rotational atherectomy and stent implantation for calcified left main lesions. Cardiol Res. 2011; 2(5): 208-217, doi: 10.4021/cr78w, indexed in Pubmed: 28357008.

22. Kübler P, Zimoch W, Kosowski M, et al. The use of rotational atherectomy in high-risk patients: results from a high-volume centre. Kardiol Pol. 2018; 76(9): 1360-1368, doi: 10.5603/ KP.a2018.0144, indexed in Pubmed: 29974449.

23. Brown AJ, Joshi FR, Cacciottolo P, et al. Coronary rotational atherectomy using burr-to-artery ratios of less than 0.5 is associated with low levels of complications, procedural success rates and favourable 12-month outcomes. Heart. 2013; 99(suppl 2): A39.2-A40, doi: 10.1136/heartjnl-2013-304019.60.

24. Cura FA, L'Allier PL, Kapadia SR, et al. Predictors and prognosis of suboptimal coronary blood flow after primary coronary angioplasty in patients with acute myocardial infarction. Am J Cardiol. 2001; 88(2): 124-128, doi: 10.1016/s0002-9149(01)01605-8, indexed in Pubmed: 11448407.

25. De Luca G, Ernst N, Zijlstra F, et al. Preprocedural TIMI flow and mortality in patients with acute myocardial infarction treated by primary angioplasty. J Am Coll Cardiol. 2004; 43(8): 1363-1367.

26. Mehta RH, Harjai KJ, Cox D, et al. Clinical and angiographic correlates and outcomes of suboptimal coronary flow inpatients with acute myocardial infarction undergoing primary percuta- neous coronary intervention. J Am Coll Cardiol. 2003; 42(10): 1739-1746, doi: 10.1016/j.jacc.2003.07.012, indexed in Pubmed: 14642681.

27. Ndrepepa G, Mehilli J, Schulz S, et al. Prognostic significance of epicardial blood flow before and after percutaneous coronary intervention in patients with acute coronary syndromes. J Am Coll Cardiol. 2008; 52(7): 512-517, doi: 10.1016/j.jacc.2008.05.009, indexed in Pubmed: 18687242.

28. Gibson CM, Murphy SA, Rizzo MJ, et al. Relationship between TIMI frame count and clinical outcomes after thrombolytic administration. Thrombolysis In Myocardial Infarction (TIMI) Study Group. Circulation. 1999; 99(15): 1945-1950, doi: 10.1161/01.cir.99.15.1945, indexed in Pubmed: 10208996.

29. Gibson CM, Cannon CP, Murphy SA, et al. Relationship of the TIMI myocardial perfusion grades, flow grades, frame count, and percutaneous coronary intervention to long-term outcomes after thrombolytic administration in acute myocardial infarction. Circulation. 2002; 105(16): 1909-1913, doi: 10.1161/01. cir.0000014683.52177.b5, indexed in Pubmed: 11997276.

30. French JK, Hyde TA, Straznicky IT, et al. Relationship between corrected TIMI frame counts at three weeks and late survival after myocardial infarction. J Am Coll Cardiol. 2000; 35(6): 1516-1524, doi: 10.1016/s0735-1097(00)00577-5, indexed in Pubmed: 10807455.

31. Armstrong PW, Fu Y, Chang WC, et al. Acute coronary syndromes in the GUSTO-IIb trial: prognostic insights and impact of recurrent ischemia. The GUSTO-IIb Investigators. Circulation. 1998; 98(18): 1860-1868, doi: 10.1161/01.cir.98.18.1860, indexed in Pubmed: 9799205.

32. Brener SJ, Barr LA, Burchenal JE, et al. Randomized, placebocontrolled trial of platelet glycoprotein IIb/IIIa blockade with primary angioplasty for acute myocardial infarction. ReoPro and Primary PTCA Organization and Randomized Trial (RAPPORT) Investigators. Circulation. 1998; 98(8): 734-741, doi: 10.1161/01. cir.98.8.734, indexed in Pubmed: 9727542. 